\title{
Kinetics and mechanism of macrocyclic complex formation
}

\author{
B.G. $\operatorname{Cox}^{1}$ and H. Schneider ${ }^{2}$ \\ I ICI Fine Chemicals Manufacturing Organisation, Hexagon House, Blackley, \\ Manchester, M9 3DA, England. \\ 2 Max-Planck-Institut für biophysikalische Chemie, D-3400, Göttingen, FRG.
}

\begin{abstract}
Macrocyclic ligands form highly selective and kinetically labile complexes with a wide range of cations, including alkali metal and alkaline earth cations. Formation rate constants are high and remarkably insensitive to Iigand structure, but decrease systematically with increasing charge density of the cation - this behaviour is qualitatively similar to that expected for the dissociative interchange mechanism ( $I_{d}$ ) common to many complexation reactions of simple monodentate iigands. The dissociation rate constants reflect directly the changes in complex stabilities within a related series of cations and over a wide range of ligand structures and solvents. A good illustration of these properties is provided by kinetic studies of the macrocyclic and macrobicyclic effects, which show that the major differences in complexation specificities and thermodynamic stabilies between complexes of open-chain and cyclic ligands are reflected almost entirely in the respective dissociation reactions. The results are considered in terms of a formal, fully-stepwise complexation model in which each of the solvent molecules in contact with the cation is replaced successively by a donor atom of the ligand.
\end{abstract}

\section{INTRODUCTION}

Metal complex formation reactions (ligand substitution reactions) with simple ligands generally occur very rapidly in aqueous solution. With the ald of fast reaction techniques, it has proved possible in some cases to resolve the overall complexation process, eq 1 , into elementary complexation steps.

$$
\mathrm{Mn}^{\mathrm{t}}+L \underset{\mathrm{k}_{\mathrm{d}}}{\stackrel{\mathrm{kf}_{\mathrm{f}}}{\rightleftharpoons}} \mathrm{ML} \mathrm{nt}
$$

These may include sequential substitution of one or more solvent molecules from the inner coordination sphere of the metal ion, conformational changes in the ligand, or protolytic equilibria of the ligand.

The kinetics of simple ligand substitution reactions have been successfully interpreted in terms of a two-step mechanism, eq 2 (ref 1,2 ), in which $S$ represents a solvent molecule. The first step is the formation of an outer-

$$
\mathrm{MS}_{\mathrm{m}} \mathrm{n}^{+}+\mathrm{L} \stackrel{\mathrm{K}_{\mathrm{OS}}}{\rightleftharpoons}\left(\mathrm{MS}_{\mathrm{m}} \mathrm{L}\right)^{\mathrm{n}+} \stackrel{\mathrm{k}_{2}}{\underset{\mathrm{k}_{-2}}{\rightleftharpoons}} \mathrm{MLS}_{\mathrm{m}-1} \mathrm{nt}+\mathrm{s}
$$

sphere complex, and the second is a rate determining reaction to form a complex in which the cation and ligand are in direct contact. In many cases the rates are only slightly dependent upon the nature of the ligand and are similar to those of solvent exchange at the cation. This is consistent with an essentially dissociative or $\mathrm{S}_{\mathrm{N}} 1$ process which, in the absence of definite evidence for the existence of a discrete intermediate, may be described as a dissociative 
interchange mechanism ( $\left.I_{d}\right)$. The formation rate constant may then be approximated by eq 3 , where $K_{o s}$ is the outer-sphere association constant and $k_{s}$ is the rate

$$
k_{f}=k_{o s} k_{s}
$$

constant for solvent exchange, determined by NMR methods.

Experimental determinations and theoretical estimates of $\mathrm{K}_{\mathrm{os}}$ values (ref 3,4 ) show them to be small - in the range 0.1-1 mol-1 dm - except for combinations of highly charged cations and anions where large electrostatic forces are involved (ref 5). The formation rate constants, therefore, are numerically closely related to the rate constants for solvent exchange at the cation. The solvent exchange rates vary enormously among cations, from between $10^{8}$ and $10^{9} \mathrm{~s}^{-1}$ for alkali and alkaline earth cations (except $\mathrm{Mg}^{2+}, \mathrm{Be}^{2+}$ ) and $\mathrm{Cu}^{2+}$, through $10^{4}-10^{8} \mathrm{~s}-1$ for $\mathrm{M}^{2+}$ transition metal cations, $10^{0} \mathrm{~s}^{-1}$ for $\mathrm{Al}^{3+}$, to $10^{-7} \mathrm{~s}^{-1}$ for certain M3+ transition metal cations, such as $\mathrm{Rh}^{3+}$ ( $r e f 6,7$ ); they are relatively independent of solvent.

The results for substitution reactions of simple ligands provide a useful framework for the discussion of complexation reactions of macrocyclic ligands but there are a number of special features of these systems which need some consideration:

(i) The striking selectivity of many of the reactions.

(ii) The high stabilities for complexes of cations such as alkali metals which are not renowned for their coordination chemistry.

(iii) The loss during complexation of most or all of the solvent molecules coordinated to the metal ion.

(iv) A combination of high specificity and rapid turnover observed for many biologically active macrocyclic ligands.

In this lecture we present a brief overview of the kinetic methods used to study the reactions and of characteristic kinetic properties of the complexes, particularly with regard to their relationship to the unusually high complex stabilities and selectivities (macrocyclic and macrobicyclic effects). The results are then discussed in terms of a simple, fully-stepwise complexation model in which each of the solvent molecules in contact with the cation is replaced successively by a donor atom of the ligand. Structures of some common ligands are included in Fig 1 .

\section{RESULTS}

The wide range of complexation and decomplexation rates occurring across the range of macrocycles and cations has prompted the use of a large number of different kinetic techniques. The conditions under which the reactions have been studied fall into two distinct categories: those pertaining to the direct monitoring of the approach to equilibrium, following rapid mixing of reagents or the perturbation of an existing equilibrium, and those relevant to competitive methods, in which a reagent is added which will interact competitively with one of the components of the complexation equilibrium via rapid pre-equilibria of irreversible reactions.

Among the former, the most common are the stopped-flow and chemical relaxation methods (ref 8 ), but NMR methods are becoming increasingly popular (ref 9-12). Most of the complexation reactions are too fast to study directly by stopped-flow, but there are a few exceptions, such as the reaction of alkaline earth cations with cryptand ligands (ref 13,14 ). Single displacement relaxation methods, such as temperature-jump and pressure-jump, have not been widely used, mainly because of difficulties in monitoring the reactions; examples are the alkali metal complexes of antibiotics of the valinomycin group, in which murexide is used as an indicator for the cations (ref 15), and of the cryptand ligands (ref 16). Stationary methods, particularly ultrasonic absorption, which allow measurement of relaxation times as low as a few nanoseconds, have been particularly valuable for studying rapid conformational changes in ligands (ref 15,17) and crown ether complexation reactions (ref 18 ). NMR methods have been used for kinetic studies involving a variety of nuclei, including $1_{\mathrm{H}}, 7_{\mathrm{Li}}, 13 \mathrm{C}, 23 \mathrm{Na}, 39 \mathrm{~K}$, and $133 \mathrm{Cs}$ (ref $9,10,19-23)$. In the majority of cases, exchange rates between free and complexed ligands or cations have been determined from the broadening and coalescence of the resonances of the two states ( $T_{2}$ measurements), but measurements based on the influence of exchange on the spin-lattice relaxation time $\left(T_{1}\right)$ have proved valuable for complexes of quadrupolar nuclei, such as $23 \mathrm{Na}$ (ref 24,25$)$. 


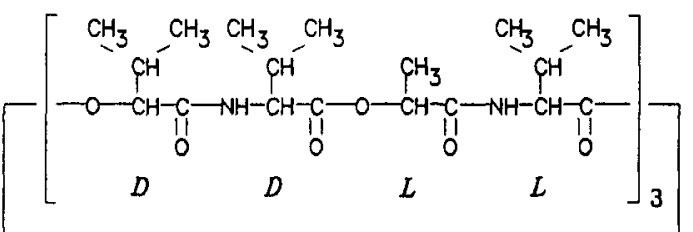

Valinomycin

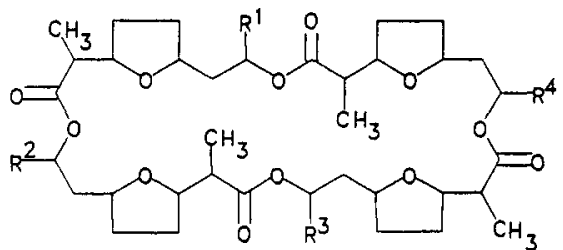

$$
\begin{array}{ll}
R^{1}=R^{2}=R^{3}=R^{4}=C_{3} & \text { Nonactin } \\
R^{1}=R^{2}=R^{3}=C_{3} \quad R^{4}=C_{2} H_{5} \quad \text { Monactin }
\end{array}
$$

\section{Macrotetralides}<smiles>C1CC2CCOCCOCCOCCOCCOCCOCCOCCOCCOC3CCCCC3OCCOCCOC2C1</smiles>

18-crown-6

dicyclohexyl-18-croum-6

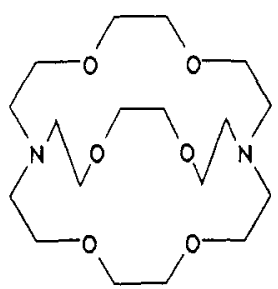

cryptand $(2,2,2)$

Fig 1. Macrocyclic ligands

Direct measurement of complexation rates as described above are frequently limited either by rate constants for complex formation which are too large (stopped-flow) or by the requirement that the position of equilibrium of the system under investigation should not lie too much to either side (relaxation methods). This leads to practical difficulties in detecting the participant species when the stability constants are greater than about $10^{5} \mathrm{M}^{-1}$. Thus, the most convenient experimental methods for determining complexation kinetics are often competitive methods, in which reagents (scavengers) are added to compete for the ligand or cation and hence to generate reaction in the thermodynamically unfavourable direction for the complexation reaction of interest. Typically, $\mathrm{H}^{+}$may be added to remove basic (eg nitrogen-containing) ligands by protonation; under favourable conditions, dissociation of the complex to form the free ligand is

rate-determining (ref 26,27 ). As the dissociation reactions of macrocyclic complexes are often relatively slow, reactions may be monitored using conventional or stopped-flow techniques.

The various kinetic methods have been used to determine the overall rate constants for complex formation, $\mathrm{k}_{\mathrm{f}}$, and dissociation, $\mathrm{k}_{\mathrm{d}}$ (eq 1 ). In some cases resolution of intermediate steps and ligand conformational changes occurring prior to or during complexation has also been possible (ref 15,17, 18). Mention should also be made of a number of interesting mechanistic features of these reactions, including acid catalysed complex dissociation (ref 24,2728 ), direct bimolecular cation-cation exchange ( $r \in f 22,23$ ), and direct intra- or intermolecular exchange of cations between ligand sites (ref 29,30). For the remainder of this lecture, however, we will concentrate on results for simple complexation equilibria, as described by eq 1 . 
Influence of ligand structure Ligands covering an extremely wide range of structural types have been studied, including very large monocyclic systems, such as valinomycin (ref 31 ) and the macrotetralides (ref 32 ), crown ethers (12-30 membered rings), macrobicyclic cryptand ligands with variable cavity size, and the formally open-chain, carboxylate ionophores, such as monensin. The most comprehensive set of data refers to methanol as solvent, and some representative values for complexation of a common cation ( $\mathrm{Na}^{+}$) are listed in Table 1.

Table 1 Complexation reactions of $\mathrm{Na}^{+}$with macrocyclic ligands in methanol at $25^{\circ} \mathrm{C}$.

\begin{tabular}{lcccc} 
Ligand & $\log \left(\mathrm{k}_{\mathrm{s}} / \mathrm{M}^{-1}\right)$ & $\mathrm{k}_{\mathrm{f}} / \mathrm{M}^{-1} \mathrm{~s}^{-1}$ & $\mathrm{k}_{\mathrm{d}} / \mathrm{s}^{-1}$ & ref \\
\hline valinomycin & 0.8 & $1.2 \times 10^{7}$ & $2 \times 10^{6}$ & $\mathrm{a}$ \\
monactin & 2.7 & $3 \times 10^{8}$ & $6 \times 10^{5}$ & $\mathrm{~b}$ \\
dinactin & 3.1 & $6.5 \times 10^{7}$ & $5 \times 10^{4}$ & $\mathrm{~b}$ \\
trinactin & 3.3 & $7.2 \times 10^{7}$ & $4 \times 10^{4}$ & $\mathrm{~b}$ \\
Cy218-C-6 & 3.7 & $2.6 \times 10^{8}$ & $5.2 \times 10^{4}$ & $\mathrm{c}$ \\
monensin & 6.4 & $2.2 \times 10^{8}$ & 87 & $\mathrm{~d}$ \\
$(2,2,2)$ & 8.0 & $2.7 \times 10^{8}$ & 2.8 & $\mathrm{e}$ \\
$(2,2,1)$ & 9.6 & $8.7 \times 10^{7}$ & $2 \times 10^{-2}$ & $\mathrm{e}$ \\
\hline
\end{tabular}

(a) ref 31; (b) ref 32; (c) E. Shchori, J Jagur-Grodzinski, and M Shporer, J.Amer.Chem.Soc., $1973,95,3842$; (d) ref 25 ; (e) ref 33 .

The most striking feature is the near constancy of the $k_{f}$ values, despite the marked variations in structure of the ligands and a change in complex stability constants, $K_{S}$, of around 9 orders of magnitude; the changes in $K_{S}$ are reflected almost entirely in the dissociation rate constants, $k_{d}$. It is also important to note the absolute magnitudes of the $k_{f}$ values, which are close to those expected for simple dissociative interchange reactions of monodentate ligands. The only exceptions to this behaviour occur for ligands which undergo substantial conformational changes on complexation, such as the cyclodecapeptide antamanide (ref 15), or small, conformationally rigid ligands, such as the cryptand $(2,1,1)$ (ref 33 ).

Cation dependence Kinetic studies of complexes of the naturally occurring macrocyclic antibiotics have been limited mainly to complexes formed with alkali metal cations, but a more extensive range of cations has been investigated with the synthetic ligands, particularly the macrobicyclic cryptand ligands. In the absence of strong, specific interactions of the type characteristic of the first-row transition metal cations, $k_{f}$ (and $k_{d}$ ) values decrease strongly with increased cation charge (Table 2, ref 34,35 ). Thus, increasing charge from $z=+1$ to $z=+2$ reduces $k_{f}$ by a factor of $10^{3}-10^{4}$ and from $z=+1$ to $z=+3$ by a factor of $10^{6}-10^{7}$.

Table 2 Influence of cation charge in complexation kinetics in water $\left(25^{\circ} \mathrm{C}\right)$.

\begin{tabular}{|c|c|c|c|c|c|c|}
\hline Cation & $r_{m} / A$ & & $2,2)$ & & & ref \\
\hline & & $k_{f} / M^{-1} s^{-1}$ & $\mathrm{k}_{\mathrm{d}} / \mathrm{s}^{-1}$ & $k_{f} / M^{-1}{ }_{s}-1$ & $\mathrm{k}_{\mathrm{d}} / \mathrm{s}^{-1}$ & \\
\hline $\begin{array}{l}\mathrm{Na}^{+} \\
\mathrm{Ca}^{2+} \\
\mathrm{Eu}^{3+}\end{array}$ & $\begin{array}{l}0.95 \\
0.99 \\
0.95\end{array}$ & $\begin{array}{c}4 \times 10^{6} \\
5.8 \times 10^{3} \\
0.35 \\
\end{array}$ & $\begin{array}{l}15.5 \\
6.5 \times 10^{-4} \\
4.1 \times 10^{-7}\end{array}$ & $\begin{array}{c}2 \times 10^{6} \\
7 \times 10^{3} \\
2.5\end{array}$ & $\begin{array}{c}1.5 \times 10^{2} \\
0.19 \\
1.1 \times 10-3\end{array}$ & $\begin{array}{l}a \\
a \\
b\end{array}$ \\
\hline
\end{tabular}

(a) ref $34 ;$ (b) ref 35 .

The influence of cationic size within a given charge type is less marked and shows up much more specifically in the dissociation rate constants. The $k_{f}$ values normally show a simple, monotonic increase with cation size, whereas $k_{d}$ values are much more sensitive to the degree of matching between the cation and ligand cavity size. Representative $k_{f}$ values for group I and group II cations are given in Table 3 . 
Table 3 Dependence of $k_{f}$ values for macrocyclic complexes on cationic size.

\begin{tabular}{|c|c|c|c|c|c|}
\hline Cation & $\mathrm{r}_{\mathrm{m}} / \mathrm{A}$ & $(18-C-6)^{a}$ & $(2,2,1) \stackrel{b}{k_{f} / M}$ & $\begin{array}{l}1\left(25^{\circ} \mathrm{C}\right) \\
\text { monensinc }\end{array}$ & valinomycind \\
\hline $\mathrm{Li}^{+}$ & 0.60 & $8 \times 10^{7}$ & $1.9 \times 10^{7}$ & $9.0 \times 10^{7}$ & \\
\hline $\mathrm{Na}^{+}$ & 0.95 & $2.2 \times 10^{8}$ & $8.7 \times 10^{7}$ & $1.1 \times 10^{9}$ & $1.2 \times 10^{7}$ \\
\hline $\mathrm{k}^{+}$ & 1.33 & $4.3 \times 10^{8}$ & $3.4 \times 10^{8}$ & $1.3 \times 10^{9}$ & $4 \times 10^{7}$ \\
\hline $\mathrm{Rb}^{+}$ & 1.48 & $4.4 \times 10^{8}$ & $4.1 \times 10^{8}$ & $2.2 \times 10^{9}$ & $5.5 \times 10^{7}$ \\
\hline $\mathrm{Cs}^{+}$ & 1.69 & $7.8 \times 10^{8}$ & & & $2 \times 10^{7}$ \\
\hline $\mathrm{Ca}^{2+}$ & 0.99 & & $1.9 \times 10^{4}$ & & \\
\hline $\mathrm{Sr} \mathrm{r}^{2+}$ & 1.13 & $6.5 \times 10^{7}$ & $9.2 \times 10^{4}$ & & \\
\hline $\mathrm{Ba}^{2+}$ & 1.35 & $1.2 \times 10^{8}$ & $1.9 \times 10^{6}$ & & \\
\hline
\end{tabular}
J.Amer.Chem.Soc., 1977,99,3240; (b) MeOH, ref 33; (c) B.G. Cox, Ng. van Truong. J. Rzeszotarska, and H. Schneider, J.Amer.Chem.Soc., 1984,106, 5965; (d) ref 15 .

Selective complexation - the macrocyclic/macrobicyclic effect There is very little unusual discrimination in the $k_{f}$ values within a group of cations of the same charge type; the selectivity associated with macrocyclic ligands comes primarily from variations in $k_{d}$ values. A limited amount only of kinetic data exists for open-chain analogues of crown ethers, but $k_{f}$ values for $\mathrm{Na}^{+}$and $\mathrm{K}^{+}$are typically around $1-5 \times 10^{8} \mathrm{M}^{-1} \mathrm{~s}^{-1}$ (cf Table 1). Thus the increased thermodynamic stability of macrocyclic ligends compared to open-chain analogues (macrocyclic effect) shows up primarily in the rate constants for complex dissociation.

A similar conclusion may be reached for the macrobicyclic (cryptand) effect, for which there is a more comprehensive set of data. Table 4 shows a comparison of results for complexation of alkaline earth cations with the closely related macrocyclic diaza-crown $(2,2)$ and the bicyclic cryptand $(2,2,2)$ ligands.

Table 4 The macrobicyclic effect: $(2,2)$ vs $(2,2,2)$ complexes of alkaline earth cations in methanol at $25^{\circ} \mathrm{C}$ ( $r e f 37$ ).

\begin{tabular}{lcccccc} 
& \multicolumn{2}{c}{$\log \left(\mathrm{K}_{\mathrm{S}} / \mathrm{M}^{-1}\right)$} & \multicolumn{2}{c}{$\log \left(\mathrm{k}_{\mathrm{f}} / \mathrm{M}^{-1} \mathrm{~s}^{-1}\right)$} & \multicolumn{2}{l}{$\log \left(\mathrm{k}_{\mathrm{d}} / \mathrm{s}^{-1}\right)$} \\
Cation & $(2,2)$ & $(2,2,2)$ & $(2,2)$ & $(2,2,2)$ & $(2,2)$ & $(2,2,2)$ \\
\hline $\mathrm{Ca}^{2+}$ & 3.5 & 8.1 & 5.0 & 4.4 & 1.48 & -3.66 \\
$\mathrm{Sr}^{2+}$ & 5.7 & 11.8 & 5.7 & 5.5 & 0.04 & -6.26 \\
$\mathrm{Ba}^{2+}$ & 5.9 & 12.9 & 6.8 & 6.7 & 0.90 & -6.20 \\
\hline
\end{tabular}

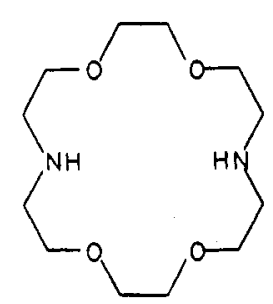

$(2,2)$

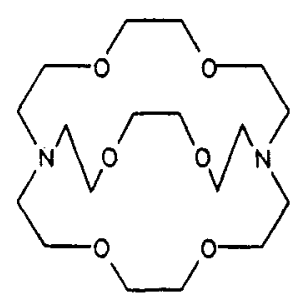

$(2,2,2)$

The most notable feature is the close agreement between the formation rate constants for the $(2,2)$ and $(2,2,2)$ complexes, despite the considerable increase in stability of the bicyclic $(2,2,2)$ ligands (macrobicyclic effect). The major differences between the two ligands then are to be seen in the dissociation reactions, with values for $(2,2,2)$ being some 5-7 orders of magnitude lower than those for $(2,2)$. 


\section{COMPLEXATION MECHANISM}

The somewhat unexpected combination of rapid formation rates and high cation solvation energies, which is characteristic of the majority of macrocyclic complexation reactions, can on $1 y$ be accommodated within an essentially stepwise reaction scheme. The kinetic properties discussed above, particularly the lack of ligand specificity in the formation reaction, point to a transition state in which there is no specific 'recognition' between the cation and Iigand, ie, the cation must be largely outside the ligand cavity, interacting only through donor atoms rotated outwards from the ligand cavity. Subsequent processes, including substitution of the remaining solvent molecules associated with the cation and any required conformational changes, to give the final stable complex must then occur relatively rapidly.

In this section we introduce a simple model, based on earlier work by Winkler on biofunctional ionophores ( $\operatorname{ef} 38$ ), in which the overall complexation reaction, eq 1 , is treated as occurring in a fully-stepwise manner in which each of the solvent molecules associated with the cation is replaced successively by a donor atom of the ligand, eq 4 .

$M^{+}+X_{0} \underset{k_{-0}}{\stackrel{k_{0}}{\rightleftharpoons}} M^{+} x_{0} \underset{k_{-1}}{\stackrel{k_{1}}{\rightleftharpoons}} M^{+} x_{1} \underset{k_{-2}}{\stackrel{k_{2}}{\rightleftharpoons}} M^{+} x_{2} \underset{k_{-3}}{\stackrel{k_{3}}{\rightleftharpoons}} \ldots \ldots . \frac{k_{m}}{\rightleftharpoons} M^{+} X_{m}$

where

$\begin{array}{ll}\mathrm{M}^{+} & : \text {fully solvated metal ion } \\ \mathrm{X}_{0} & : \text { fully solvated ligand } \\ \mathrm{M}^{+} \mathrm{X}_{\mathrm{O}} & : \text { outer-sphere complex } \\ \mathrm{M}^{+} \mathrm{X}_{i} & : \text { metal ion coordinated through } i \text { of m ligand donor atoms } \\ \mathrm{k}_{0}, \mathrm{k}_{-0} \quad: \text { diffusion controlled reactions }\end{array}$

The observed rate constants, $k_{f}$ and $k_{d}$, pertaining to this model may be obtained in a straightforward manner by applying the steady state assumption to the intermediate states, ie $d\left[M^{+} X_{1}\right] / d t=0$ (only the initial $\left(M^{+}+X_{0}\right.$ ) and final $\left(\mathrm{M}^{+} \mathrm{X}_{\mathrm{m}}\right)$ states are present in measurable concentrations):

$$
\begin{aligned}
& k_{f}=k_{0} k_{1} k_{2} \ldots \ldots k_{m} / N \\
& k_{d}=k-o_{k-1} k_{-} \ldots \ldots k-m / N
\end{aligned}
$$

where

$$
\begin{aligned}
N= & k_{1} k_{2} k_{3} \ldots k_{m}+k_{-o} k_{2} k_{3} \ldots h_{m}+k_{-o} k_{-1} k_{3} \ldots k_{m}+\ldots . \\
& \cdots \cdots+k_{-o} k_{-1} k_{-2} \ldots k-m+1
\end{aligned}
$$

Useful insight into the complexation process may be obtained from eq 5 in its general form (ref 38 ), but the equations take a particularly simple form with and exact algebraic solution when we assume that all of the intermediate steps are equivalent; $\underline{i e}, k_{i}=k_{1}, k_{-i}=k_{-1}$, and $k_{i}=k_{i} / k_{-i}=k_{1}$. Then the stability constant, $K_{S}$, is related to the individual constants by eq 6 , and the formation

$$
\mathrm{K}_{\mathrm{S}}=\mathrm{K}_{\mathrm{OS}}\left(\mathrm{K}_{\mathrm{i}}\right)^{\mathrm{m}}
$$

rate constant, $k_{f}$, by eq $7 ; k_{d}$ may be obtained from $k_{s} / k_{f}$. It is thus a simple

$$
k_{f}=\frac{k_{0} k_{1}}{k_{1}+k_{-0}\left(1+\sum k_{i}-1\right)}
$$

matter to calculate the equilibrium and rate constants for the successive steps in eq 4 from given values of $k_{f}$ and $k_{s}$ ( $\underline{e g}$, using a typical value of $m=6$ ).

The simplified model should apply most closely in the limiting case of a very flexible ligand, but it is of interest to apply it to the present results for crown and aza-crown ethers ('2-dimensional' ligands) and cryptands ('3-dimensional' ligands) as illustrated in Fig 2. The crown ethers, which have high conformational flexibility, form complexes in which there is normally some residual interaction between the cation and solvent, represented by $M^{+} X_{5}$. 


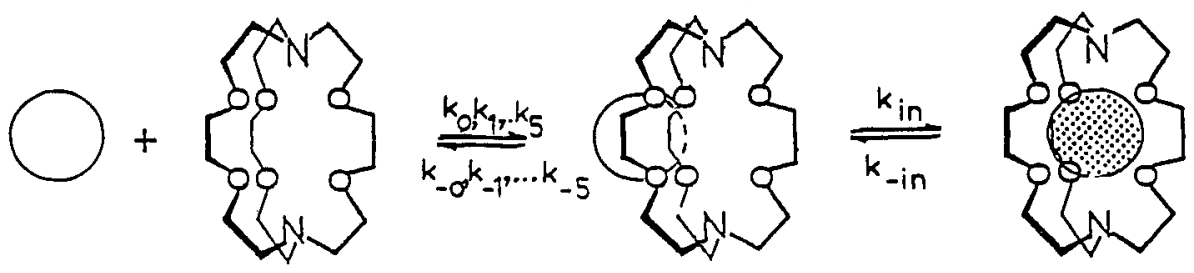

Fig 2 Model for complex formation between $\mathrm{Na}^{+}$and $(2,2,2)$ : steps represented by $k_{o}, k_{1}, \ldots k_{5}$ are common to crown ether complexation.

Cryptate formation, however, requires an additional step ( $k_{i n}, k_{-}$in) in which the cation enters the ligand cavity, shedding any remaining solvent molecules from the inner coordination sphere of the cation. This final step results in an increase in $\mathrm{K}_{\mathrm{s}}$ by a factor of $10^{4}-10^{7}$ for alkali and alkaline earth complexes (the cryptate or macrobicyclic effect). A summary of the results obtained is given in Table 5 .

Table 5 Analysis of crown ether and cryptand complex formation in methanol according to a stepwise complexation model.

\begin{tabular}{|c|c|c|c|c|c|c|}
\hline \multirow[b]{2}{*}{ Complex } & \multirow{2}{*}{$\underset{2 \times 10^{10}}{\stackrel{5 \times 10^{9}}{\rightleftharpoons}}$} & \multirow{2}{*}{$\begin{array}{c}{ }^{1+x_{0}} \frac{k_{i}}{k_{d^{b}}} \\
\frac{k^{b}}{2}\end{array}$} & \multirow{2}{*}{$\begin{array}{r}\mathrm{M}^{\mathrm{n}+} \mathrm{X}_{1} \\
\mathrm{k}_{i} \mathrm{~b}\end{array}$} & $\stackrel{\mathrm{k}_{1}}{\rightleftharpoons} \ldots \mathrm{M}^{\mathrm{n}+\mathrm{X}_{5}}$ & \multicolumn{2}{|c|}{$\stackrel{k_{\text {in }}}{\rightleftharpoons} M^{n+X_{6}}$} \\
\hline & & & & $k_{-} i^{b}$ & $k_{\text {in }}{ }^{b}$ & $k_{-i n} b$ \\
\hline $\begin{array}{l}\mathrm{Na}\left(\mathrm{Cy}_{2} 18 \mathrm{C} 6\right)^{+} \\
\mathrm{Na}(2,2,2)^{+}\end{array}$ & $\begin{array}{c}3 \times 10^{8} \\
2.7 \times 10^{8}\end{array}$ & $\begin{array}{c}5.2 \times 104 \\
2.87\end{array}$ & $\begin{array}{l}8.1 \times 10^{8} \\
8.1 \times 10^{8}\end{array}$ & $\begin{array}{l}1.7 \times 10^{8} \\
1.7 \times 10^{8}\end{array}$ & $8.1 \times 10^{8}$ & $1.0 \times 10^{4}$ \\
\hline $\begin{array}{l}\mathrm{Ca}(2,2)^{2+} \\
\mathrm{Ca}(2,2,2)^{2+}\end{array}$ & $\begin{array}{c}1 \times 10^{5} \\
3.2 \times 10_{4}\end{array}$ & $\begin{array}{c}30 \\
2.2 \times 10-4 \\
\end{array}$ & $\begin{array}{l}2.4 \times 10^{5} \\
2.4 \times 10^{5} \\
\end{array}$ & $\begin{array}{l}4.2 \times 10^{4} \\
4.2 \times 10^{4} \\
\end{array}$ & $2.4 \times 10^{5}$ & 5.6 \\
\hline
\end{tabular}

(a) $\mathrm{M}^{-1} \mathrm{~s}^{-1} ;$ (b) $\mathrm{s}^{-1}$.

The results in Table 5, which are also illustrated schematically in Fig 3 , highlight many of the main features of macrocyclic complex formation for main-group cations, and may be summarised as follows:

1. The absolute magnitude of $\mathrm{k}_{i}$ for $\mathrm{Na}+$ complexation $\left(\mathrm{k}_{i}=8 \times 10^{8} \mathrm{~s}^{-1}\right)$ is very close to the rate constant for solvent exchange at $\mathrm{Na}^{+}$. The formation rate constants of $\mathrm{ca} 3 \times 10^{8} \mathrm{M}^{-1} \mathrm{~s}^{-1}$ for complex formation by the crown ethers, cryptands, and monactin (Table 2) must be approaching the maximum possible value for macrocyclic complexation of $\mathrm{Na}^{+}$.

2. For $\mathrm{Ca}^{2+}, \mathrm{k}_{i}$ values $\left(2 \times 10^{5} \mathrm{~s}^{-1}\right)$ are some three orders of magnitude lower than that of solvent exchange. The relatively lower $\mathrm{k}_{i}$ values for higher-charge-density cations indicate less efficient compensation for solvation loss (greater disruption of solvation) during complexation. This may be because significant ion-solvent interactions persist beyond the first solvation shell for the $2+$ and $3+$ cations.

3. The model is in good agreement with widespread kinetic evidence that the transition state for complex formation lies close to the reactants with the cation retaining most of its solvent shell.

4. Complexation systems whose behaviour approximates to that of the model will be experimentally very difficult to resolve into individual steps. Such a resolution will be most likely when, for example, a difficult conformational change leads to an additional high energy barrier between reactants and products. 


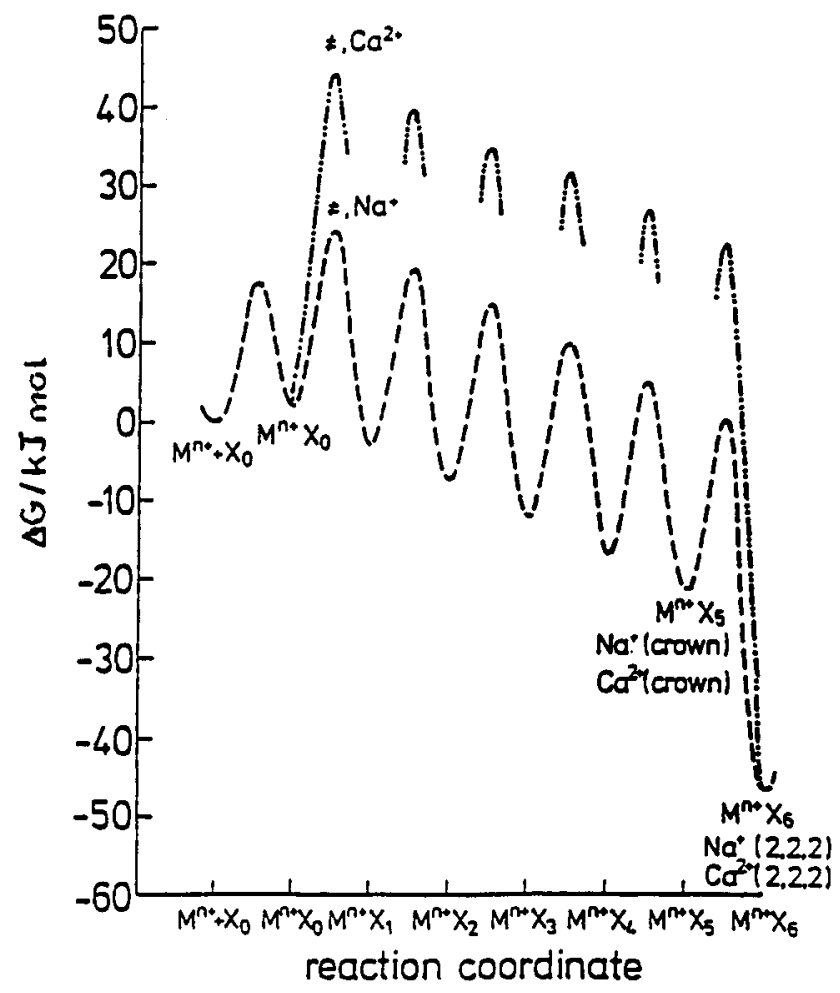

Fig 3 Reaction profile for stepwise complexation model

Finally, we consider a rather different system, namely that of complexation of $\mathrm{Ag}^{+}$ by the nitrogen-containing ligands $(2,2)$ and $(2,2,2)$. The stabilities of complexes formed by $\mathrm{Ag}^{+}$with these ligands and their open-chain analogues appear to be dominated by the strong and partially covalent interactions between $\mathrm{Ag}^{+}$and the nitrogen atoms of the ligand (ref 39 ). Table 6 gives the stability constants for the silver complexes of the diazapolyether ligands (2) $\left(\mathrm{HNCH}_{2} \mathrm{CH}_{2}\left(\mathrm{OCH}_{2} \mathrm{CH}_{2}\right){ }_{2} \mathrm{NH}\right)$, $(2,2)$, and $(2,2,2)$ in acetonitrile ( $r e f 40)$.

Table 6 Stability constants $\left(\log \mathrm{K}_{\mathrm{s}}\right.$ ) for complexes of $\mathrm{Ag}^{+}$with the diazapolyether ligands $(2),(2,2)$, and $(2,2,2)$ in acetonitrile at $25^{\circ} \mathrm{C}$ (ref 40 ).

\begin{tabular}{llcc}
\hline ligand & $(2)$ & $(2,2)$ & $(2,2,2)$ \\
$\log \mathrm{K}_{\mathrm{S}}$ & 7.40 & 7.76 & 8.92 \\
\hline
\end{tabular}

There is a steady increase in $\mathrm{K}_{\mathrm{S}}$ in the series from the open-chain (2) to the bicyclic $(2,2,2)$, but the effect is very small compared with similar comparisons for complexes of the alkali metal or alkaline earth cations, for which the ligand structure plays a dominant role. The dependence of stability constant upon ligand structure for the silver complexes, although small, is real: within the cryptand ligands $K_{S}$ is a maximum for the intermediate sized $(2,2,1)$ independent of solvent, eg, in acetonitrile $\log \mathrm{K}_{\mathrm{s}}(2,1,1)=7.8, \log \mathrm{K}_{\mathrm{s}}(2,2,1)=11.2, \log \mathrm{K}_{\mathrm{s}}=8.9$. Nevertheless, it is clear that the dominant interaction in these complexes is between $\mathrm{Ag}^{+}$and nitrogen, given the similarity in the stability constants of $(2,2)$ and $(2,2,2)$ despite the latter ligand having four more oxygen atoms and a more to favourable bicyclic structure.

In view of this we have adopted the kinetic model illustrated in Fig 4 for the silver-diazapolyether system in which the key steps are the successive formation of the two $\mathrm{Ag}^{+} \ldots \mathrm{N}$ bonds, again preceded by the formation of an outer-sphere complex (not shown). 
(a)
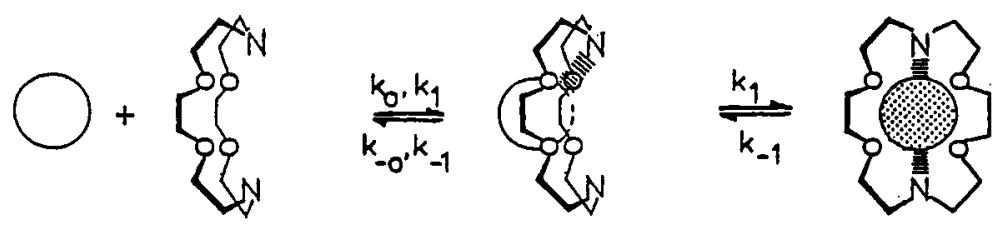

(b)
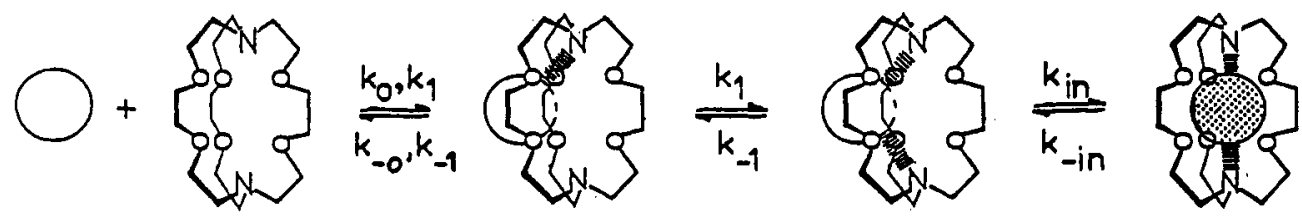

Fig 4 Model for complexation of $\mathrm{Ag}^{+}$with (a) $(2,2)$ and (b) $(2,2,2)$.

An analysis of the rates and equilibria of the complexation reactions of $(2,2)$ and $(2,2,2)$ based on eq $4-6$ with $m=2$ and 3 respectively, leads to the results in Table 7. This corresponds to an equilibrium constant for each $\mathrm{Ag}^{+} \ldots \mathrm{N}$ bond $\left(\mathrm{K}_{1}=\right.$ $\left(\mathrm{K}_{\mathrm{s}} / \mathrm{K}_{0}\right)^{1 / 2}$ ) of $1.1 \times 10^{4}$. In contrast to the corresponding alkali metal and alkaline earth complexes, the equilibrium constant for the exclusive $\Rightarrow$ inclusive complexation $\left(K_{\text {in }}=17\right)$ is very small. A similar conclusion is reached from results covering the complete range of water-acetonitrile mixtures, although in water $\mathrm{K}_{\text {in }}$ is slightly larger, $\mathrm{K}_{\text {in }}=80$.

Table 7 Analysis of $\mathrm{Ag}^{+}-(2,2)$ and $-(2,2,2)$ complex formation in acetonitrile according to a stepwise complexation model (Fig 4).

\begin{tabular}{lcccccc} 
Complex & $\mathrm{k}_{\mathrm{f}} / \mathrm{M}^{-1} \mathrm{~s}^{-1}$ & $\mathrm{k}_{\mathrm{d}} / \mathrm{s}^{-1}$ & $\mathrm{k}_{1} / \mathrm{s}^{-1}$ & $\mathrm{k}_{-1} / \mathrm{s}^{-1}$ & $\mathrm{k}_{1}$ & $\mathrm{~K}_{\text {in }}$ \\
\hline $\mathrm{Ag}(2,2)^{+}$ & $2.0 \times 10^{9}$ & 35 & $6.7 \times 10^{9}$ & $6.2 \times 10^{5}$ & $1.1 \times 10^{4}$ & \\
$\mathrm{Ag}(2,2,2)^{+}$ & $5.4 \times 10^{8}$ & 0.55 & $6.7 \times 10^{9}$ & $6.2 \times 10^{5}$ & $1.1 \times 10^{4}$ & 17 \\
\hline
\end{tabular}

\section{REFERENCES}

1. M. Eigen and K. Tamm, 2. Elektrochem., $1962,66,93$.

2. M. Eigen and R.G. Wilkins, Adv.Chem.Ser.No49, 1965,55.

3. R.G. Wilkins, The Study of Kinetics and Mechanism of Reactions of Transition Metal Complexes', Allyn and Bacon, Boston, 1974.

4. M. Eigen, 2. Phys.Chem., NF, $1954, \underline{1}, 176$.

5. H. Rauh and $w$. Kroche, Ber. Bunsenges. Phys. Chem., 1979, 83, 518.

6. J. Burgess, 'Metal Ions in Solution' Ellis Horwood, Sussex, 1978, Chil.

7. Y. Marcus, 'Ion Solvation', Wiley, Chichester, 1985, Ch 4.

8. H. Strehlow and W. Knoche, 'Fundamentals of Chemical Relaxation', Verlag Chemie, N.Y., 1977.

9. B. Eliasson, K.M. Larson, and K. Kowalowski, J.Phys.Chem., 1985, 89, 258.

10. A. Delville, H.D.H. Stover, and C. Detellier, J.Amer.Chem.SoC., 1985, 107, 4172 .

11. M. Shamispur and A.I. Popov, J.Phys.Chem., 1986,90,5997.

12. P. Szczygid, M. Shamispur, K. Hellenga, and A.I. Popov, J.Phys.Chem., $1987,91,1252$.

13. V.M. Loyola, R. Pizer, and R.G. Wilkins, J.Amer.Chem.Soc., 1977,99, 7185.

14. B.G. Cox, Ng, van Truong, and H. Schneider, J.Amer.Chem.SoC., 1984,106, 1273 .

15. W. Burgermeister and R. Winkler-Oswatitsch, Top.Curr.Chem., 1977, $\underline{69}, 91$. 
16. K. Henko, B. Tummler, and G. Maass, Angew. Chem., 1977, 89, 567.

17. H. Schneider, S. Rauh, and S. Petrucci, J.Phys.Chem., 1981, 85, 2287.

18. L.J. Rodriguez, E.M. Eyring, and S. Petrucc1, J.Phys.Chem., 1989, $93,6357$.

19. J.M. Lehn, J.P. Sauvage, and B. Dietrich, J.Amer.Chem.Soc., 1970,92, 2916.

20. Y.M. Cahen, J.L. Dye, and A.I. Popov, J.Phys.Chem., 1975, 79, 1292 .

21. E. Schmidt and A.I. Popov, J.Amer.Chem.Soc., 1983,105, 1873 .

22. M. Shamispur and A.I. Popov, J.Phys.Chem., 1987,91,447.

23. H.D.H. Stöver, A. Delville, and C. Detellier, J.Amer.Chem.Soc, 1985, 107, 4167 .

24. H. Degani, Biophys.Chem., 1977,6, 345 .

25. E. Amat, B.G. Cox, J. Rzeszotarska, and H. Schneider, J.Amer.Chem.Soc., $1988,110,3368$.

26. B.G. Cox, D. Knop, and H. Schnelder, J. Phys. Chem., $1980,84,320$.

27. B.G. Cox, J. Garcia-Rosas, and H. Schneider, J. Amer.Chem.Soc., 1981, 103, 1054.

28. G. Krause, E. Gre11, A.M. Albrecht-Gary, D.W. Boyd, and J.P. Schwing, in 'Physical Chemistry of Transmembrane Ion Motions' ed. G. Sprach, Elsevier, Amsterdam, 1983,255.

29. J.M. Lehn and M.E. Stubbs, J.Amer.Chem.Soc, $1974,96,4011$.

30. B.G. Cox, Ng. van Truong, and H. Schneider, J.Chem.Soc., Faraday I, 1984, 80,3285 .

31. Th. Funck, F. Eggers, and E. Gre11, Chimia, 1972,26,637.

32. P.B. Chock, F. Eggers, M.Eigen, and R. Winkler, Biophys.Chem., 1977,6, 239.33.

B.G. Cox, H. Schneider, and J. Stroka, J.Amer.Chem.Soc., 1978, 100, 4746.

34. B.G. Cox, J. Garcia-Rosas, and H. Schneider, J.Amer.Chem.SoC., 1981, 103, 1054.

35. E. Lee, O.A. Gansow, and M.J. Weaver, J.Amer.Chem.Soc., 1980,102, 2278.

36. B. Tümmler, G. Mass, E. Weber, W. Wehner, and F. Vögtle, J.Amer.Chem.SOC., $1977,99,4683$.

37. B.G. Cox, P. Firman, I. Schneider, and H. Schneider, Inorg.Chem., 1988, 27,4018 .

38. R. Winkler, 'Kinetik und Mechanisms der Alkali- und Erdalkalimetallkomplexbildung in Methanol', Dissertation, Gottongen-Wien, 1969.

39. T. Buchard, 'Solvensabhangigkeit der Komplexbildung vom Silberion mit Mono- und Bicyclischen Diazapolyethern.' Dissertation, Dortmund, 1984.

40. B.G. Cox, J. Stroka, P. Firman, I. Schneider, and H. Schneider, Aust.J.Chem., $1983, \underline{36}, 2133$. 